\title{
- 0 engajamento dos usuários do Facebook em relação à comunicação da Covid-19: uma análise da Prefeitura Municipal de Curitiba (Paraná, Brasil)
}

\author{
The Facebook user's engagement regarding the Covid-19 \\ communication: an analysis of the City Hall of Curitiba (Paraná, \\ Brazil)
}

Carlos Mello Garcias ${ }^{a}$

Murilo Noli da Fonsecaa (iD

Larissa Maria da Silva Ferentza,* (D)

Nicole Santos Accioly Rodrigues da Costa ${ }^{\text {(D) }}$

\begin{abstract}
RESUMO: Com a disseminação do novo coronavírus no Brasil, o aumento da utilização da internet cresceu substancialmente devido ao isolamento social no início da pandemia. Aliado a este fator, diversos órgãos públicos passaram a compartilhar conteúdos informativos por meio das mídias sociais. Deste modo, cada vez mais se faz necessário utilizar ferramentas que permitam compreender a efetividade das divulgações realizadas quanto ao enfrentamento da doença. O objetivo do artigo é examinar o engajamento dos seguidores da página oficial da Prefeitura Municipal de Curitiba no Facebook, a partir da análise da tipologia e do teor das postagens, além do comportamento do respectivo público ao interagir com tais posts, durante os primeiros meses (entre 31/12/2019 e 30/04/2020) da pandemia da Covid-19 no município. A metodologia tem caráter quantitativo, sendo utilizado o software Facepager para coleta dos dados. Após a coleta, foi realizada a análise dos tipos de conteúdo e dos tipos de mídia adotadas pela Prefeitura, caracterizando as publicações de acordo com sua temática principal. Como principais resultados, observase que as publicações aumentaram de forma crescente, em conjunto com o número de casos e óbitos registrados. Não obstante, os tipos de mídia mais utilizados são as fotos, assim como os conteúdos mais compartilhados se referem à comunicação em tempo real, a sensibilização e educação e o relatórios de atividades realizadas. Conclui-se que a análise de ferramentas de uso público, como o Facebook, é muito importante para que os gestores locais compreendam o alcance da informação em momentos de crise.
\end{abstract}

Palavras-chave: Mídias Sociais; Covid-19; Pandemia; Comunicação; Gestão de Riscos.

ABSTRACT: The spread of the new coronavirus in Brazil meant that there was a substantial increase in the use of the internet due to social isolation at the beginning of the pandemic. Allied to this factor, several public agencies started to share informative content through social media. Thus, it is increasingly necessary to use tools that allow to understand the effectiveness of the disclosures made regarding the coping with the disease. The purpose of the article is to examine the engagement of followers of the official page of the Curitiba City Hall on Facebook, from the analysis of the typology and content of the posts, in addition to the behaviour of the respective public when interacting with such posts, during the first months (between 12/31/2019 and 4/30/2020) of the Covid-19 pandemic in the municipality. The methodology has a quantitative character, using the Facepager software for data collection. After the collection, an analysis was made of the types of content and types of media that the Municipality has adopted, characterizing the publications according to their main theme. As main results, it is observed that the publications increase in an increasing way, together with the number of registered cases and deaths. Nevertheless, the most used media types are photos, as well as the most shared content refer to real-time communication, awareness and education and reporting of activities carried out. It is concluded

a Pontifícia Universidade Católica do Paraná, Curitiba, PR, Brasil.

*Correspondência para/Correspondence to: Larissa Maria da Silva Ferentz. E-mail: ferentzengenharia@gmail.com.

Recebido em/Received: 15/08/2020; Aprovado em/Approved: 28/12/2020.

Artigo publicado em acesso aberto sob licença CC BY 4.0 Internacional (C)( 
that the analysis of tools for public use, such as Facebook, is very important for local managers to understand the scope of information in times of crisis.

Keywords: Social media; Covid-19; Pandemic; Communication; Risk management.

\section{INTRODUÇÃO}

No final de 2019, um grupo de pacientes com doenças respiratórias agudas foi vinculado a um mercado atacadista de frutos do mar em Wuhan, província de Hubei, China. O patógeno foi identificado como um novo betacoronavírus de RNA envelopado (Lu et al. 2020), atualmente designado "coronavírus de síndrome respiratória aguda grave 2" (SARS-CoV-2), que possui similaridade filogenética ao SARS-CoV (Zhu et al. 2020). Desde então, milhões de pessoas em diferentes países foram infectadas pelo coronavírus 2019 (Covid-19). Em 11 de março, a Organização Mundial da Saúde (OMS) declarou o surto de coronavírus de rápida disseminação, alta circulação e mortalidade (Huang et al. 2020) como pandemia. No Brasil, até o dia 13 de agosto foram contabilizados 3.275 .520 casos e 106.523 mortes $-3,3 \%$ de taxa de letalidade (Brasil 2020).

Com as incertezas geradas pela Covid-19, o público, especialmente os grupos mais vulneráveis, como aqueles com comorbidades, apresenta uma demanda maior por mensagens transparentes e consistentes em tempo real, as quais auxiliam na construção da confiança. A comunicação clara e eficaz dos riscos é de suma importância para orientar as partes interessadas a adotar certos comportamentos desejados, como o distanciamento social e bons hábitos de higiene, além de dissipar notícias falsas em tempos de pandemia. O histórico inicial do surto da Covid-19, entretanto, apresentou uma falta de transparência de informações e demora no processo de tomada de decisão, inibindo a eficácia da comunicação de risco e amplificando os impactos (Zhang, Li, Chen 2020).

Em contraste com a pandemia da SARS, de 2003, e da H1N1, de 2009, a resposta das pessoas está sendo facilitada pelo fluxo de informações da transmissão da mídia tradicional e, em particular, pelo mundo em rede gerado pela emergência das mídias sociais. As mídias sociais vêm crescendo como mecanismo de comunicação de informações sobre os riscos (Feldman et al. 2016). Uma em cada três pessoas no mundo estão envolvidas em mídias sociais atualmente, assim como, dois terços da população já faz uso da Internet (Ortiz-Ospina e Roser 2020). No Brasil, por exemplo, cerca de 140 milhões de pessoas estavam utilizando a internet em janeiro de 2020, o que representa um acréscimo de 11 milhões entre abril de 2019 e o primeiro mês deste ano (Kemp 2020).

As mídias sociais têm sido utilizadas como um meio de comunicação entre a população e os órgãos gestores públicos. O consumo dessas plataformas pela gestão local e agências governamentais têm crescido nos últimos anos (Johannessen, Flak Sæbø 2012), informando aos cidadãos sobre como se precaver e responder adequadamente aos riscos. Elas são vistas como fontes efetivas para o compartilhamento de conteúdo formal e informal de informação para diversos públicos, criando um veículo de comunicação bidirecional entre cidadãos e o governo. Tais mídias se referem a plataformas baseadas na Internet que facilitam o compartilhamento de informações em computadores e dispositivos móveis, como as redes sociais (por exemplo, Facebook e Twitter), serviços de compartilhamento de mídia, serviços de mapas web, mensagens de texto, salas de bate-papo, fóruns de discussão e blogs, etc. (Lindsay 2011). 
O uso generalizado de tais plataformas fornece acesso direto a uma quantidade sem precedentes de conteúdo. Levando em conta as preferências e atitudes dos usuários, os algoritmos medem e facilitam a promoção de conteúdo e a divulgação de informações (Southwell et al. 2019). O público tem a possibilidade de expressar suas críticas - positivas ou negativas - em relação às tomadas de decisão do governo local com o objetivo de gerenciar o desdobramento do risco, que no caso do presente trabalho, é a pandemia causada pela Covid-19.

Com isso, o envolvimento das partes interessadas pode ser medido de diferentes maneiras, fornecendo informações valiosas sobre as suas interações. Essas medidas podem servir como métricas para avaliar a eficácia da mídia social utilizada na comunicação de riscos e crises (Sharma et al. 2017). No entanto, diversos autores indicam que o feedback do cidadão via mídia social não resulta em mudanças governamentais (Magro 2012).

Baseado nisso, o presente trabalho tem como objetivo examinar o engajamento dos seguidores da página oficial da Prefeitura Municipal de Curitiba no Facebook, a partir da análise da tipologia e do teor das postagens, além do comportamento do respectivo público ao interagir com tais posts, durante os primeiros meses (entre 31/12/2019 e 30/04/2020) da pandemia da Covid-19 no município. Para tanto, buscou-se utilizar uma abordagem de caráter quantitativo, com a finalidade de medir o envolvimento das partes interessadas e identificar tendências de comunicação e interação entre gestão municipal e usuário. Porém, embora os resultados mostrem quais tipos de conteúdo e mídia são os mais curtidos, compartilhados e comentados pelos envolvidos, eles não possibilitam entender como elas utilizam determinadas informações e se as transformam em práticas.

Portanto, o presente trabalho pretende contribuir com a comunidade científica ao desenvolver uma metodologia combinada, de caráter qualitativo (a partir da análise de conteúdo das postagens) e quantitativo, capaz de medir o envolvimento das partes interessadas em uma mídia social (Facebook), a partir da análise de critérios dispostos em decretos municipais (no caso desse trabalho, de Curitiba). O produto elaborado possui a capacidade de diagnosticar os pontos fortes e fracos da utilização da mídia, auxiliando na melhoria da comunicação de um risco. Além disso, ele pode ser utilizado como um instrumento de gestão regional ao fornecer informação de qualidade aos seguidores, com um potencial de transformar, a longo prazo, a cultura deles, a partir da conscientização dos cidadãos em relação à mitigação de riscos.

\section{MÉTODO}

Neste estudo foi realizada uma análise de dados do Facebook, pois ele é considerado a plataforma social que oferece as possibilidades mais claras para uma interação mais sustentada entre os cidadãos e as autoridades locais, já que os usuários podem curtir, comentar e compartilhar as publicações postadas na rede social (Ellison, Hardey 2013). Em adição a isso, no Brasil, cerca de $90 \%$ dos usuários dessa plataforma possuem idade entre 16 e 64 anos, enquanto o Instagram é utilizado por 79\% desse público e o Twitter, por $48 \%$ (Kemp 2020).

A página oficial da Prefeitura Municipal de Curitiba no Facebook foi escolhida em virtude de sua interatividade. São quase 1 milhão de seguidores, número que vem aumentando significativamente desde 2013. Muitos deles são residentes de outros municípios e, até mesmo, estados. A capital do Paraná, localizada na região sul do Brasil (Figura 1), possui diversos prêmios nacionais e internacionais, com destaque aos de 
2015, onde a Prefeitura conquistou duas categorias na maior premiação da área de mídias sociais do país: Prêmio Share (Curitiba 2015).

\section{Figura 1: Localização de Curitiba}

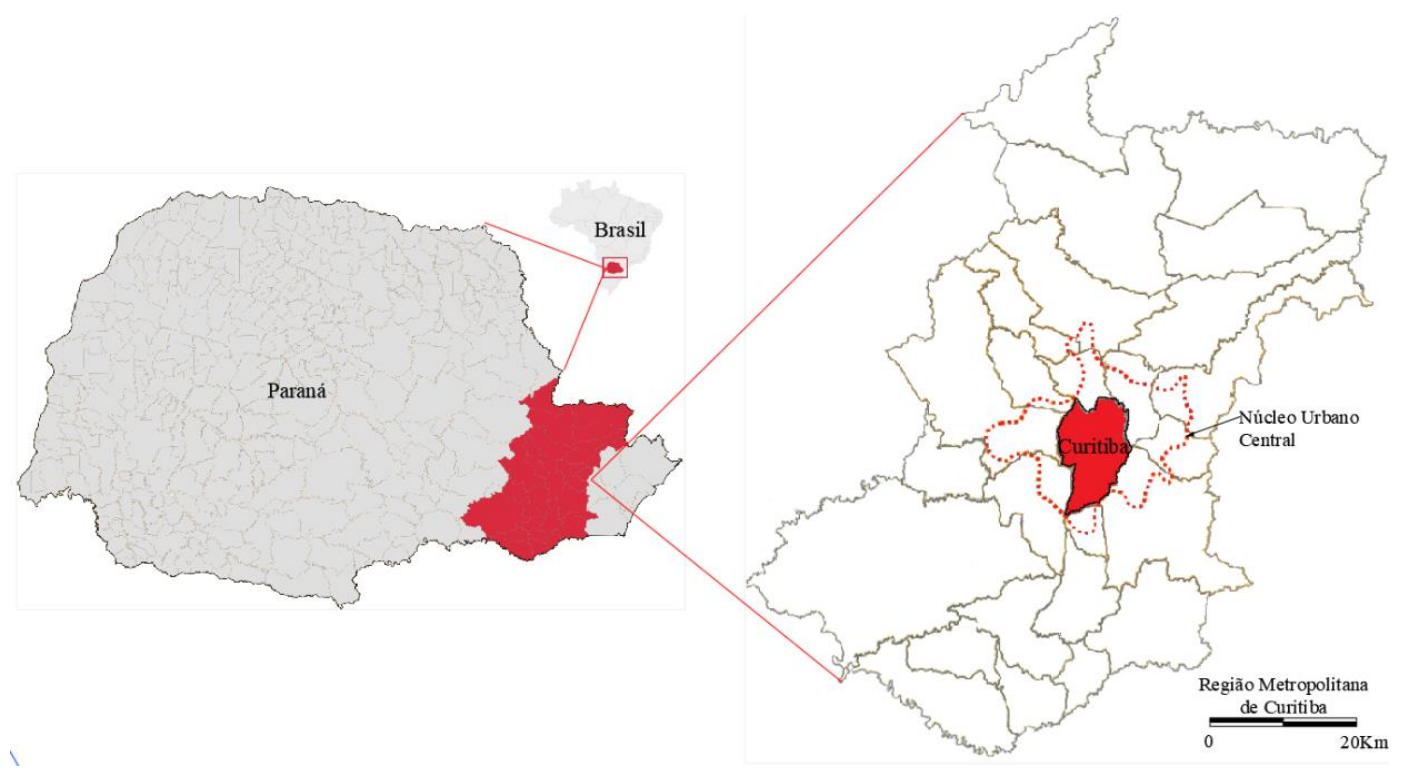

Fonte: Ferentz, Garcias e Setim (2020).

Para compreender a importância deste cenário, em comparação às outras cidades brasileiras, os seguidores representam 32\% a mais que a página de São Paulo (Curitiba tem $15 \%$ da população da cidade paulistana, onde residem 12,250 milhões), 35\% da página do Rio de Janeiro e $97 \%$ de Brasília. Essas são as três cidades que concentram a maior população per capita do Brasil.

\section{Coleta de dados}

A recuperação dos dados ocorreu em 13 de maio de 2020, tendo como recorte temporal o período compreendido entre os dias 31 de dezembro de 2019 e 30 de abril de 2020. Os fins de semana foram contabilizados, considerando a atuação 24 horas e 7 dias por semana da gestão municipal. Para tanto, utilizou-se o software livre Facepager (Jünger, Keyling 2020). Os dados extraídos foram armazenados em um banco de dados relacional para permitir uma investigação aprofundada. Posteriormente, houve a remoção das mensagens não relacionadas à Covid-19 e à adição automática das categorias de postagem do Facebook. No total, 262 posts foram analisados. Os dados referentes ao número de fãs da página (seguidores) foram coletados pelo método observacional.

Cada postagem do Facebook contém as seguintes informações recuperadas: mensagem, tipos de mensagem, história da mensagem, data e hora da postagem, link para a postagem original e número de reações, comentários e compartilhamentos. Para calcular o envolvimento dos usuários, adotou-se a proposta de Bonsón e Ratkai (2013). Nela, a popularidade é calculada a partir do número de postagens curtidas, o comprometimento pelo número de comentários feitos e a viralidade pela quantidade de compartilhamentos. Ela foi aprimorada por Bonsón et al. (2017), onde foi inserida uma fórmula para calcular o engajamento dos usuários, que é a soma das categorias anteriores (Quadro 1). É importante salientar que apenas $P_{3}, C_{3}$ e V3 são destacadas, 
pois são independentes da quantidade de postagens (Bonsón, Ponte e Carvajal-Trujillo 2015). Tais métricas possibilitam o uso de categorias de conteúdo para analisar tendências no Facebook, como as realizadas por Bonsón, Ponte e Carvajal-Trujillo (2015) e De Rosário, Martín e Peréz (2016).

Quadro 1: Métricas do Facebook para envolvimento das partes interessadas

\begin{tabular}{|c|c|c|c|}
\hline Nome & Ponto & Fórmula & Medidas \\
\hline \multirow{3}{*}{ Popularidade } & $\mathrm{P} 1$ & $\begin{array}{l}\text { Postagens curtidas/ } \\
\text { total de postagens }\end{array}$ & $\begin{array}{l}\text { Porcentagem de postagens que } \\
\text { foram curtidas }\end{array}$ \\
\hline & $\mathrm{P}_{2}$ & $\begin{array}{l}\text { Total de curtidas/ } \\
\text { total de postagens }\end{array}$ & Média de curtidas por postagem \\
\hline & $P_{3}$ & $(\mathrm{P} 2 /$ número de fãs $) \times 1000$ & $\begin{array}{l}\text { Popularidade de mensagens } \\
\text { entre fãs }\end{array}$ \\
\hline \multirow{3}{*}{ Comprometimento } & $\mathrm{C}_{1}$ & $\begin{array}{l}\text { Posts com comentários/ } \\
\text { total de posts }\end{array}$ & $\begin{array}{l}\text { Porcentagem de postagens com } \\
\text { comentários }\end{array}$ \\
\hline & $\mathrm{C} 2$ & $\begin{array}{l}\text { Total de comentários/ } \\
\text { total de postagens }\end{array}$ & $\begin{array}{l}\text { Média de comentários por } \\
\text { postagem }\end{array}$ \\
\hline & $\mathrm{C}_{3}$ & (C2/número de fãs) × 1000 & $\begin{array}{l}\text { Compromisso de mensagens } \\
\text { entre os fãs }\end{array}$ \\
\hline \multirow{3}{*}{ Viralidade } & $\mathrm{V}_{1}$ & $\begin{array}{l}\text { Posts compartilhados/ } \\
\text { total de posts }\end{array}$ & $\begin{array}{l}\text { Porcentagem de postagens } \\
\text { compartilhadas }\end{array}$ \\
\hline & $V_{2}$ & $\begin{array}{l}\text { Total de compartilhamentos/ } \\
\text { total de posts }\end{array}$ & $\begin{array}{l}\text { Média de compartilhamentos } \\
\text { por postagem }\end{array}$ \\
\hline & $v_{3}$ & $\left(V_{2} /\right.$ número de fãs $) \times 1000$ & $\begin{array}{l}\text { Viralidade das mensagens entre } \\
\text { os fãs }\end{array}$ \\
\hline Engajamento & $\mathrm{E}$ & $P_{3}+C_{3}+V_{3}$ & $\begin{array}{l}\text { Índice de engajamento das } \\
\text { partes interessadas }\end{array}$ \\
\hline
\end{tabular}

Fonte: Bonsón e Ratkai (2013); Bonsón et al. (2017).

De maneira geral, o conteúdo compartilhado nas páginas do Facebook pode ser categorizado em dois tipos principais: (1) tipo de conteúdo da publicação e (2) tipo de mídia adotada no processo comunicacional. No primeiro caso, ele é o instrumento que estimula a interação. A sua análise tem sido amplamente empregada para avaliar o conteúdo e os canais de comunicação, como publicidade, histórias da mídia e sites (Yun et al. 2008). As postagens também podem ser enriquecidas com o emprego de recursos de multimídia, como as fotos, vídeos, hiperlinks e eventos, que apresentam diferentes níveis de interatividade. Estudos mostram que vídeos e textos, que requerem mais tempo de assimilação, promovem menor envolvimento dos cidadãos do que as fotos (Brookes 2010; Luarn, Lin, Chiu 2015; Cvijikj e Michahelles 2011).

\section{Codificação dos dados}

Nesse estudo foram utilizados os seguintes tipos de mídia: link, "ao vivo", foto, status e vídeo. As categorias de link, foto, status e vídeo foram atribuídas automaticamente pelo software Facepager. As postagens "ao vivo" foram identificadas por meio do 
campo de histórias, e as postagens, inicialmente codificadas como vídeos, foram recodificadas em conformidade. Em relação ao tipo de conteúdo, o esquema de codificação foi baseado em Desvars-Larrive et al. (2020) e na legislação municipal, sobretudo os decretos municipais $n^{\circ} 450$ e $n^{\circ} 470$ (Curitiba 2020a, 2020b), a resolução $\mathrm{n}^{\circ} 1$ (Curitiba 2020C), a portaria $\mathrm{n}^{\circ} 6$ (Curitiba 2020d) e o Plano de Contingência para resposta às emergências em saúde pública do município (Curitiba 2020e). Deste modo, categorias e subcategorias de análise foram definidas. No total, o esquema de codificação é composto por 2 categorias e 15 subcategorias (Quadro 2).

Quadro 2: Categorias de codificação

\begin{tabular}{|c|c|c|}
\hline Categoria & Subcategoria & Definição \\
\hline \multirow{13}{*}{ Doença } & \multirow{7}{*}{$\begin{array}{l}\text { Sensibilização } \\
\text { e educação }\end{array}$} & Medidas sanitárias de prevenção e controle da doença \\
\hline & & $\begin{array}{l}\text { Mensagens que alteram o cumprimento do prazo de } \\
\text { obrigatoriedades, como o pagamento do ISS, vigência de licença }\end{array}$ \\
\hline & & $\begin{array}{l}\text { Recomendações comportamentais para o aumento da } \\
\text { autoproteção e proteção da família (Ex: ligar 156). }\end{array}$ \\
\hline & & Recomendações comportamentais em casos de sintomas \\
\hline & & $\begin{array}{l}\text { Informações sobre riscos, incluindo suas características, como } \\
\text { sintomas, transmissão, tratamento, grupo de risco, retorno de } \\
\text { viagens, isolamento, suspensão de eventos e serviços; }\end{array}$ \\
\hline & & $\begin{array}{l}\text { Mensagens apresentando atividades educacionais e de inovação e } \\
\text { notícias e instruções sobre exercícios de proteção }\end{array}$ \\
\hline & & Mensagens sobre atividades de saúde física e emocional \\
\hline & \multirow{2}{*}{ Atenção } & $\begin{array}{l}\text { Mensagens que alertam a população sobre as áreas mais vulneráveis } \\
\text { ao risco de contágio }\end{array}$ \\
\hline & & $\begin{array}{l}\text { Mensagens que informam os serviços públicos e as atividades } \\
\text { essenciais, que devem permanecer em funcionamento }\end{array}$ \\
\hline & $\begin{array}{l}\text { Comunicação } \\
\text { em tempo real }\end{array}$ & $\begin{array}{l}\text { Mensagens contendo informações sobre a evolução da doença em } \\
\text { tempo real (casos, óbitos) - boletim epidemiológico }\end{array}$ \\
\hline & $\begin{array}{l}\text { Pedido de } \\
\text { suporte para } \\
\text { ações sociais }\end{array}$ & $\begin{array}{l}\text { Mensagens endereçadas diretamente à população para: } \\
\text { - Pedir ajuda durante as intervenções; } \\
\text { - Impor ou proibir comportamentos, a fim de reduzir o contágio }\end{array}$ \\
\hline & $\begin{array}{l}\text { Distanciament } \\
\text { o Social }\end{array}$ & $\begin{array}{l}\text { Informações sobre reduzir a frequência e a proximidade do contato } \\
\text { entre as pessoas, a fim de diminuir o risco de transmissão. Exemplos } \\
\text { de distanciamento social incluem cancelamento de eventos e } \\
\text { restrição de acesso a locais públicos }\end{array}$ \\
\hline & $\begin{array}{l}\text { Restrição de } \\
\text { viagem }\end{array}$ & $\begin{array}{l}\text { A restrição inclui alerta de viagem, triagem de entrada e saída, } \\
\text { restrições internas, fechamento de fronteiras e cordão sanitário }\end{array}$ \\
\hline \multirow[t]{2}{*}{$\begin{array}{l}\text { Ações da } \\
\text { gestão } \\
\text { local }\end{array}$} & $\begin{array}{l}\text { Apresentação } \\
\text { de funcionários } \\
\text { e voluntários }\end{array}$ & $\begin{array}{l}\text { Mensagens sobre a participação dos servidores (públicos, privados), } \\
\text { cidadãos, individualmente ou em grupo, em: } \\
\text { - exercícios de intervenção em áreas vulneráveis } \\
\text { - cursos de treinamento; }\end{array}$ \\
\hline & Recursos & $\begin{array}{l}\text { Mensagens sobre compras realizadas para melhorar a capacidade de } \\
\text { resposta adquirindo novos recursos materiais }\end{array}$ \\
\hline
\end{tabular}




\begin{tabular}{|c|c|}
\hline & $\begin{array}{l}\text { Mensagem sobre os recursos humanos e materiais que estão sendo } \\
\text { utilizados em resposta à pandemia }\end{array}$ \\
\hline $\begin{array}{l}\text { Segurança } \\
\text { pública }\end{array}$ & $\begin{array}{l}\text { Mensagens sobre a fiscalização de locais públicos, a fim de evitar } \\
\text { aglomerações e garantir a segurança do coletivo }\end{array}$ \\
\hline \multirow{2}{*}{$\begin{array}{l}\text { Mensagens de } \\
\text { compaixão }\end{array}$} & $\begin{array}{l}\text { Mensagens pelas quais a gestão municipal expressa sua compaixão } \\
\text { pelas pessoas afetadas pela doença }\end{array}$ \\
\hline & Mensagens para recordar as vítimas da doença \\
\hline $\begin{array}{l}\text { Relatórios de } \\
\text { atividades }\end{array}$ & $\begin{array}{l}\text { Mensagens que apresentam relatórios sobre a atividade } \\
\text { desenvolvidas sobre a doença pela gestão municipal (protocolos, } \\
\text { manuais, guias, notas técnicas e informativas). }\end{array}$ \\
\hline $\begin{array}{l}\text { Anúncio de } \\
\text { emprego }\end{array}$ & Anúncios de emprego nas unidades de saúde \\
\hline $\begin{array}{l}\text { Recrutamento } \\
\text { de voluntários }\end{array}$ & Anúncios de recrutamento de voluntários \\
\hline $\begin{array}{l}\text { Promoção de } \\
\text { aplicativos e } \\
\text { mídias sociais }\end{array}$ & $\begin{array}{l}\text { Mensagens que promovem outros canais de mídia social ou o } \\
\text { aplicativo móvel desenvolvido para comunicação de risco }\end{array}$ \\
\hline \multirow{2}{*}{$\begin{array}{l}\text { Serviço } \\
\text { governamental }\end{array}$} & Atividades e responsabilidades das autoridades responsáveis \\
\hline & Contatos das autoridades e responsáveis \\
\hline
\end{tabular}

Fonte: Os autores, com base em Desvars-Larrive et al. (2020); Curitiba (2020a, 2020b, 2020c, 2020d, 2020e).

A codificação foi feita manualmente e cada postagem foi classificada em apenas um código. Popularidade, comprometimento, viralidade e engajamento foram calculados para ambos os tipos.

\section{RESULTADOS}

\section{Publicações}

A comunicação de risco sobre o novo coronavírus na página da Prefeitura de Curitiba no Facebook começou no dia 07 de fevereiro, poucas semanas após a divulgação do surto em Wuhan, na China. Essa primeira postagem tratou-se de um "ao vivo" (live) com uma médica infectologista do Centro de Epidemiologia da Secretaria Municipal de Saúde, que explicou o que já se sabia sobre os sintomas e formas de contágio da doença da Covid-19, além de responder às dúvidas enviadas por internautas sobre o tema. No total, foram 1.232 reações, que compreendem 1.010 likes, 89 compartilhamentos, 59 reações e 74 comentários. O crescente número de casos em todo o mundo, sobretudo na Europa, no mês de fevereiro, e a confirmação do primeiro caso no Brasil, no dia 26, levou a uma nova publicação na página. Ela consistiu em uma foto acompanhada de um texto com esclarecimento sobre a doença, indicando quais são os sintomas e as principais recomendações de prevenção, como lavar as mãos com frequência e cobrir nariz e boca ao espirrar.

No dia 11 de março, em virtude da acelerada expansão da doença e de suas consequências no mundo, a Organização Mundial da Saúde (OMS) elevou o status de surto para pandemia. A partir do dia 12 de março há o registro dos primeiros casos na 
capital paranaense. Como resultado dessa situação e das medidas adotadas pelas autoridades públicas para conter a expansão da doença, como a quarentena e distanciamento social, as publicações sobre o tema na página se tornaram diárias (Figura 2). Em alguns dias, inclusive, houve mais de uma postagem.

\section{Figura 2: Publicações sobre a Covid-19 no Facebook da Prefeitura de Curitiba e o número de casos e óbitos na cidade}

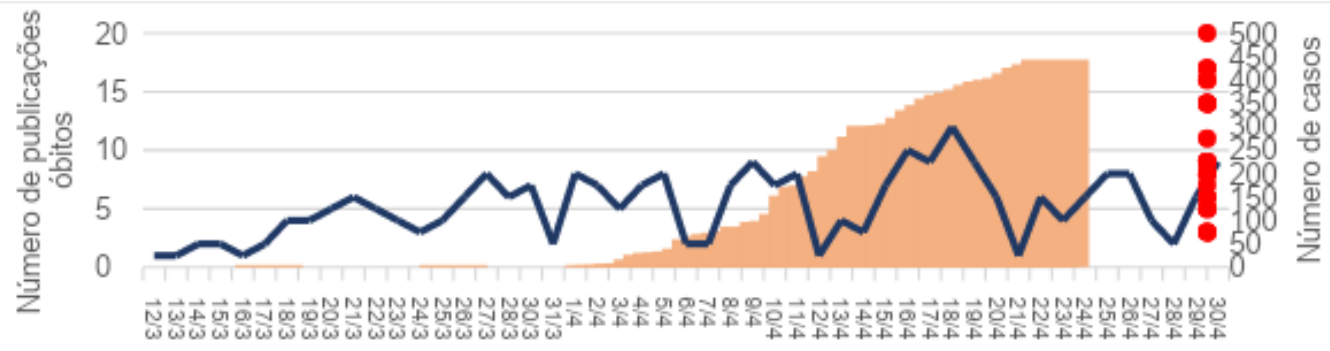

\footnotetext{
Masos —Publicações @ Mortes

Fonte: Os autores (2020), com base em levantamento próprio e Secretaria de Saúde (2020).
}

Porém, o aumento do número de publicações não manteve um crescimento constante, como ocorreu com os números de novos casos e mortes. Essas evidências demonstram que não há uma correlação direta entre os números de publicações da página oficial da Prefeitura Municipal de Curitiba e os números de casos e mortes ocorridos no período analisado em questão. Uma possível justificativa para esse fenômeno é que o tempo necessário para que haja a apropriação de uma nova cultura pela sociedade é de médio a longo prazo. Outra possível causa para esse acontecimento é a rápida disseminação do novo coronavírus e as lacunas de desconhecimento profissional e da população em relação ao comportamento do vírus dentro e fora do organismo humano.

\section{Tipos de informações comunicadas e mídias utilizadas}

Em relação ao teor das postagens codificadas, em categoria e subcategoria, e a qualificação por tipo de conteúdo postado, a maior parte $(74,4 \%)$ das postagens foram relacionadas à categoria "doença", sendo que $71,4 \%$ são relacionadas à comunicação em tempo real (34,7\%), sensibilização e educação (24,8\%) e distanciamento social (11,8\%). Os outros $25,6 \%$ das postagens fazem referência às "ações da gestão local". Dentre elas, $12,6 \%$ são referentes aos relatórios de atividades, $6,1 \%$ aos aplicativos móveis e outras mídias sociais, $2,7 \%$ aos recursos e 2,3\% à apresentação de funcionários e voluntários.

As mídias mais utilizadas para comunicar tais informações foram as "fotos", "ao vivo" e "vídeo", totalizando 67,2\%, 19,4\% e 12,7\% publicações cada, respectivamente. As fotos são utilizadas principalmente para a comunicação em tempo real (30,7\%), sensibilização e educação (26,1\%), relatório de atividades (12,5\%) e distanciamento social (11,4\%). As postagens "ao vivo" foram usadas na comunicação em tempo real (69,2\%), especialmente na divulgação do boletim epidemiológico e principais recomendações de prevenção, sendo seguida pela sensibilização e educação (17,3\%). 
Os vídeos, por sua vez, encontram-se relacionados aos relatórios de atividades (31,3\%), distanciamento social $(31,3 \%)$ e sensibilização e educação $(28,1 \%)$. Já os status são restritos à comunicação em tempo real (50\%) e sensibilização e educação (50\%). A relação de todas as postagens e o tipo de conteúdo divulgado, encontra-se na Figura 3.

Figura 3: Quantificação das postagens por subcategoria

Postagens sobre a Covid-19 no Facebook da Prefeitura de Curitiba

Recrutamento de voluntários

Anuncio de emprego

Atividades de apoio à segurança pública Atenção

Apresentação de funcionários e voluntários

Pedido de suporte para ações sociais

Recursos

Aplicativos móveis e outras mídias sociais

Distanciamento Social

Relatórios de atividades

Sensibilização e educação

Comunicação em tempo real

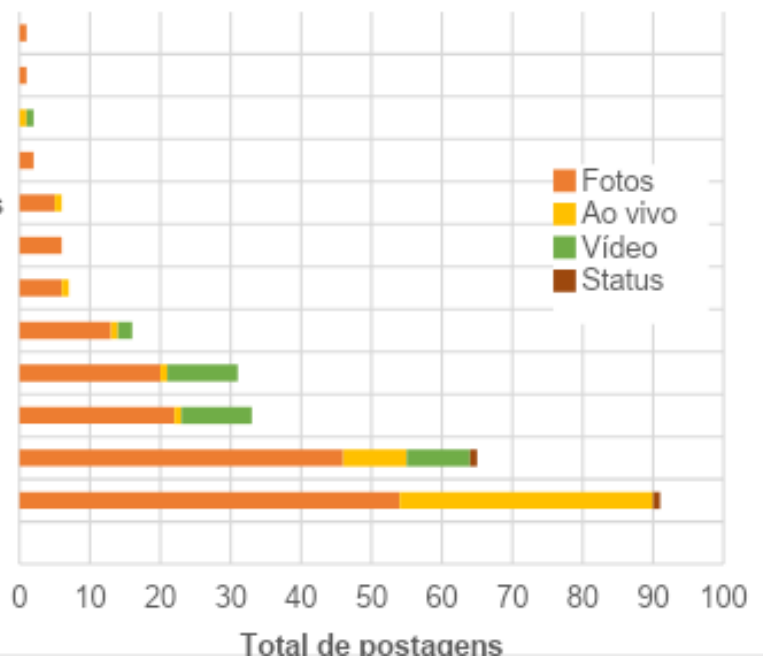

Fonte: Os autores (2020).

Baseado nessa circunstância, pode-se afirmar que a Prefeitura Municipal de Curitiba utiliza a sua página no Facebook principalmente como uma ferramenta de divulgação do boletim epidemiológico e recomendações comportamentais, auxiliando na manutenção sanitária e colocando em segundo plano as postagens relacionadas à infraestrutura necessária para enfrentar o novo coronavírus, como: anúncio de empregos (1), recrutamento de voluntários (1), serviço governamental (1) e atividades de apoio à segurança pública (2).

\section{Padrões de envolvimento em relação à mídia e ao tipo de conteúdo}

Os padrões de engajamento em relação à mídia indicam que os vídeos geraram o mais alto nível de engajamento, principalmente em virtude de sua elevada popularidade. As fotos são o segundo tipo de mídia mais atraente, embora seja o mais reagido, comentado e compartilhado. O status apresenta maior comprometimento do que as demais categorias. Já o "ao vivo" é o tipo de mídia que apresenta o menor engajamento (Quadro 1). Ou seja, os diferentes tipos de engajamento mostram que as reações são a forma mais comum utilizada, seguidas por compartilhamento e comentários, corroborando estudos anteriores (Bonsón, Royo, Ratkai 2015; Meltzer, Stefănescu, Ozunu 2018).

Quadro 1: Engajamento das partes interessadas por tipo de mídia.

\begin{tabular}{|l|c|c|c|c|}
\hline Tipo de mídia & Popularidade & Comprometimento & Viralidade & Engajamento \\
\hline Foto & 0,62 & 0,09 & 0,29 & 1,00 \\
\hline
\end{tabular}




\begin{tabular}{|l|l|l|l|l|}
\hline Vídeo & 2,26 & 0,07 & 0,27 & 2,60 \\
\hline Story & 0,09 & 0,30 & 0,15 & 0,55 \\
\hline Status & 0,22 & 0,32 & 0,41 & 0,95 \\
\hline
\end{tabular}

Fonte: Os autores (2020).

No que se refere ao tipo de conteúdo, as ações da gestão local apresentam maior nível de engajamento do que as postagens relacionadas à categoria "doença". Por exemplo, o serviço governamental se destaca em virtude de sua elevada popularidade e comprometimento (Quadro 2). A única postagem atrelada a essa categoria ocorreu no dia 06 de abril e consiste em orientações de como solicitar o auxílio emergencial, disponibilizado pelo governo federal às pessoas em situação de vulnerabilidade. Outro tema que apresenta alto engajamento, devido principalmente à sua viralidade, é a participação de funcionários públicos/privados e/ou voluntários em exercícios de intervenção ou cursos de treinamento. No dia 29 de abril, por exemplo, a postagem feita pela página estava relacionada ao recebimento de máscaras faciais produzidas por uma professora do Centro de Educação Infantil (CEI) do Expedicionário, bem como às atividades pedagógicas desenvolvidas pelos professores desta unidade escolar.

Quadro 2: Engajamento das partes interessadas por tipo de conteúdo.

\begin{tabular}{|l|c|c|c|c|}
\hline Critério & Popularidade & Comprometimento & Viralidade & Engajamento \\
\hline Comunicação - tempo real & 0,70 & 0,21 & 0,17 & 1,08 \\
\hline Sensibilização e educação & 0,60 & 0,09 & 0,31 & 1,01 \\
\hline Relatórios de atividades & 1,13 & 0,07 & 0,20 & 1,39 \\
\hline Distanciamento Social & 0,53 & 0,10 & 0,26 & 0,90 \\
\hline $\begin{array}{l}\text { Aplicativos móveis e outras } \\
\text { mídias sociais }\end{array}$ & 0,60 & 0,03 & 0,07 & 0,70 \\
\hline Recursos de & 1,21 & 0,08 & 0,37 & 1,66 \\
\hline $\begin{array}{l}\text { Pedido de suporte para } \\
\text { ações sociais }\end{array}$ & 0,27 & 0,03 & 0,12 & 0,42 \\
\hline $\begin{array}{l}\text { Apresentação } \\
\text { funcionários e voluntários }\end{array}$ & 0,49 & 0,28 & 1,25 & 2,03 \\
\hline Atenção de ànoio à & 0,39 & 0,06 & 0,04 & 0,36 \\
\hline $\begin{array}{l}\text { Atividades de } \\
\text { segurança pública }\end{array}$ & 0,15 & 0,21 & 0,52 & 1,11 \\
\hline $\begin{array}{l}\text { Anuncio de emprego } \\
\text { Roluntários }\end{array}$ & 0,17 & 0,67 & 0,99 \\
\hline Serviço governamental & 0,78 & 3,42 \\
\hline
\end{tabular}

Fonte: Os autores (2020).

Por outro lado, ações de recrutamento de voluntários, atenção, pedido de suporte para ações sociais apresentaram os níveis mais baixos de engajamento. No primeiro caso, houve somente uma publicação, ocorrida no dia 19 de março, com baixo 
comprometimento e viralidade. Trata-se de uma postagem que solicitava profissionais e estudantes da área da saúde para atuar como voluntários no combate à Covid-19 em 111 unidades básicas de saúde e nove unidades de pronto atendimento, a fim de apoiar as equipes de triagem dos pacientes e outras atividades que possam tornar mais ágil o atendimento. Já as ações de atenção ocorreram duas vezes (dias 27 de março e 13 de abril) e são referentes às medidas que definem os serviços e atividades essenciais, nos âmbitos público e privado, que devem ser resguardados na cidade.

A partir do objetivo de pesquisa, quanto ao engajamento dos usuários da página oficial da Prefeitura de Curitiba no Facebook, os resultados buscaram apresentar as tipologias, categorizações e quantitativos das postagens e sua respectiva interação com os seguidores. Nesse momento, é fundamental o aprofundamento da temática em relação ao conteúdo compartilhado, a fim de compreender o perfil da página da Prefeitura de Curitiba e suas estratégias quanto o combate ao novo coronavírus, durante o período de pesquisa.

\section{DISCUSSÃO}

A utilização de dados fornecidos por ferramentas de uso público permite aos pesquisadores compreender o nível de fornecimento de informações sobre a Covid-19 pelo poder público. No caso dessa doença, é possível analisar o que a gestão pública está compartilhando, quais são os enfoques e os tipos de mídia mais usados para tal (Lucas, Elliot, Landman 2020). Para acompanhar o desenvolvimento das tecnologias de comunicação e informação (TIC), diversos órgãos públicos têm utilizado as mídias sociais para ampliar sua comunicação com a sociedade, já que elas possibilitam a criação de comunidades virtuais, ambientes colaborativos e mecanismos de interação (Silva 2015). Esse cenário permite uma maior agilidade e transparência, além de ser uma iniciativa inovadora para a promoção dos serviços que estão sendo desenvolvidos (Mergel 2012). Logo, em tempos de pandemia, o uso dessas mídias se mostra como um importante instrumento para divulgação de trabalhos e orientações ao público.

No Brasil, a utilização de mídias e da internet por órgãos públicos é regida pela Lei n. ${ }^{\circ}$ 12.965 de 2014, a qual estabelece os princípios, direitos e deveres para o uso da Internet no país. A referida lei busca atender aos princípios da Constituição, que visa a publicidade de maneira legal, moral e impessoal. Em seu artigo n. 24 há dois incisos que se destacam. $O$ inciso I tem como premissa que sejam estabelecidos mecanismos multiparticipativos, os quais envolvam o governo, o setor privado, a sociedade e a academia. Não obstante, o inciso VI também vista que haja a publicidade e a disseminação de informação pública.

Dentre as principais ferramentas utilizadas pelos usuários, estão as redes sociais. $\mathrm{O}$ Facebook é a rede social mais usada no mundo, com mais de 2 bilhões de usuários. No Brasil, até o fim de 2019 , cerca de $75 \%$ da população utilizava a plataforma, sendo o terceiro país com maior número de cadastrados (Twist 2020). Com a decretação da pandemia da Covid-19, no início da quarentena no país, o consumo de mídias sociais alcançou uma média de 40\% (Kantar 2020). Essa preocupação, pelo emprego de ferramentas como o Facebook por parte da prefeitura de Curitiba, pôde ser observada durante a coleta de dados da pesquisa. É visível o aumento significativo de informações compartilhadas, em especial àquelas voltadas à temática em estudo. Esse compartilhamento é cada vez mais necessário e importante, tendo em vista que a comunicação durante a pandemia deve ser cada vez mais digital (Deslandes, Coutinho 2020). 
A página oficial da Prefeitura de Curitiba no Facebook é considerada como um dos maiores casos de sucesso do Brasil (Santana, Souza 2017). Os gestores sentiram a necessidade de utilizar a plataforma como um meio de realizar retornos mais rápidos para o atendimento ao público, e receber críticas e sugestões para melhoria de aspectos relacionados ao planejamento e à gestão da cidade. Um exemplo se refere à participação social na atualização da Lei Orçamentária Anual, a qual obteve quase quatro vezes mais contribuições pelo Facebook do que pelos outros meios adotados (Santos, Harmata 2013).

A representatividade da prefeitura no Facebook está atrelada às estratégias adotadas para maior interação com a população. Nesse quesito, destaca-se os ajustes realizados pelos gestores a fim de se estabelecer um equilíbrio entre a divulgação das ações do executivo municipal com publicações de humor, como, por exemplo, sobre o tempo de Curitiba, que é alvo de piada entre os moradores por ser uma capital fria e chuvosa na maior parte do ano. Essa estratégia chamou a atenção de diversos estados, resultando, inclusive, em interações entre páginas de outras prefeituras (Barriento, Tavares, Leite 2015). A partir disso, é possível compreender a força que a Prefeitura possui em sua página do Facebook. Isso também nos faz entender a importância das publicações e compartilhamentos que têm sido feitos pelos gestores sobre a Covid-19. Por isso, a maior parte das publicações realizadas no período da pesquisa se enquadram na temática da saúde.

A sociedade é formada por indivíduos em rede que se apresentam conectados, mesmo em tempos de isolamento. Por isso, os governos tendem a se adaptar em conjunto às tecnologias, a fim de alcançar o maior número de alcance das publicações. Essa relação é necessária, visto que a movimentação das postagens com curtidas, compartilhamentos e comentários, é realizado por usuários, independentemente do que esteja sendo publicado (Castells 2006). Diferentemente dos estudos que apontam que os vídeos apresentam um menor envolvimento dos cidadãos (Brookes 2010; Cvijikj e Michahelles 2011; Luarn, Lin, Chiu 2015), o engajamento dos usuários na página da prefeitura de Curitiba apresentou-se maior para as publicações desse formato. O vídeo é considerado pela plataforma como um elemento de linguagem universal. Esse perfil dos usuários vai ao encontro dos achados de Vries et al. (2012) e Sabate et al. (2014), que expõem um alto envolvimento nas postagens contendo vídeos.

No entanto, a interação dos usuários quanto às reações, compartilhamentos e comentários é maior nas fotos. As fotos são o tipo mais popular de compartilhamento, sendo que mais da metade das postagens da prefeitura são desse formato. Isso também foi observado no comprometimento dos usuários quanto ao conteúdo publicado no status. Ou seja, existe uma maior interação entre os próprios fãs da página. O Facebook recebe, em média diária, 250 milhões de fotos. A preferência dos usuários por esse formato se dá pela rapidez, tanto do compartilhamento quanto de quem visualizará o conteúdo. No caso dos vídeos, além de tempo de edição, também é preciso considerar que os usuários terão de dedicar mais tempo para assistir (Sbarai e Honorato, 2012).

É importante destacar que o engajamento é um indicador essencial para as páginas das prefeituras municipais e demais entidades governamentais. Quanto maior for $\mathrm{o}$ engajamento dos usuários, maior será a possibilidade de que os temas que estão sendo compartilhados, serão absorvidos pela população. Por isso, durante a pandemia, os gestores podem realizar o acompanhamento da evolução de suas postagens e das interações dos usuários, a fim de definir as estratégias mais eficientes para a proteção das comunidades. 
Baseado no volume de informações que são compartilhadas, os órgãos oficiais também têm tomado o cuidado, implementando as medidas necessárias para combater a disseminação de notícias falsas ou fake news. Ainda não há, no Brasil, uma lei específica para o compartilhamento de notícias falsas. Todavia, a divulgação de informações fraudulentas que provoquem desconfiança e alarme social, é crime conforme a Lei $n^{\circ} 12.965$ de 2014. Recentemente, em 2017, foi apresentado o Projeto de Lei $n^{\circ} 473$, para incluir no Código Penal a criminalização da divulgação de notícia falsa na internet (Carvalho, Kanffer 2018).

Destaca-se que essa é uma temática importante a ser levantada pois o compartilhamento de fake news gera o descrédito que a população começa a apresentar perante as informações recebidas via mídia (Vosoughi et al. 2018). Isso faz com que a população não siga as orientações por não acreditar que sejam verdade ou, em outros casos, a acreditar nas notícias falsas e praticarem ações que vão de encontro às recomendações oficiais. Conforme pesquisa da Organização de Pesquisa e Petições Online, aproximadamente 9 em cada 10 brasileiros já receberam algum tipo de notícia falsa sobre o novo coronavírus, especialmente através do Whatsapp e Facebook (Avaaz 2020).

Mesmo quando as informações de perfis oficiais do governo são verídicas, a quantidade excessiva de informações recebidas faz com que alguns cidadãos se sintam incapazes em diferenciar quais mensagens apresentam informações inconsistentes ou não (Moreno, Fuentes-Lara, Navarro 2020). Como forma de reduzir a quantidade de notícias falsas na plataforma, o Facebook tem tomado algumas medidas de controle. Dentre elas, estão o fornecimento de informações apuradas para os usuários, a remoção de conteúdos duvidosos e a adoção de inteligência artificial na detecção de conteúdos abusivos sobre a Covid-19 (Jin 2020). Tais iniciativas permitem evitar que ocorra pânico coletivo.

Anteriormente à pandemia de Covid-19, cerca de $84 \%$ das prefeituras faziam pelo menos uma publicação na semana (Santana, Souza 2017). Com a evolução da doença e a necessidade de atualização constante, o aumento de publicações foi observado na pesquisa. Esse fenômeno justifica a razão pela qual as informações relacionadas à comunicação em tempo real sobre a pandemia foram as mais divulgadas pela prefeitura.

Após o primeiro caso confirmado da Covid-19 em Curitiba, em 12 de março, a prefeitura declarou Estado de Emergência em Saúde Pública no município, instituindo as primeiras medidas de distanciamento social e isolamento. Ainda no fim desse mês, com 66 casos confirmados, os eventos foram proibidos e as aulas e atividades não essenciais suspensas (Moura 2020). No mês de abril ocorreu a primeira morte registrada no município ocorrida logo após a contratação de mais profissionais de saúde e ao aumento de leitos de UTI (Unidade de Terapia Intensiva). O uso de máscaras em espaços públicos também passou a ser obrigatório nas primeiras semanas desse mês. Embora o número de casos confirmados tenha atingido 391 e 9 óbitos na metade do mês, a reabertura parcial do comércio foi autorizada. Essa situação entrou em contradição com as recomendações de isolamento e distanciamento social da Secretaria Municipal da Saúde, já que a flexibilização incentivou a circulação de pessoas no comércio. Como resultado, duas semanas após a reabertura, foram registrados 614 casos confirmados e 23 óbitos (Moura 2020).

É importante destacar que essas medidas de distanciamento social, além do uso de máscaras e limpeza frequente das mãos, fazem parte da segunda temática mais compartilhada pela prefeitura: a sensibilização e educação populacional. Ao se tratar de uma doença nova, onde o descobrimento de medidas mais efetivas vai ocorrendo a 
cada dia, a atualização de informação para a população é essencial. Enfatizar as ações individuais para proteção e prevenção da doença, se faz cada vez mais necessário, tendo em vista que ainda não existe cura para a Covid-19.

Com a evolução da doença, as postagens da prefeitura acompanharam as decisões internacionais e nacionais quanto às medidas de prevenção e distanciamento social. Nos primeiros meses da Covid-19, os órgãos oficiais tentavam entender as principais ações a serem tomadas e, portanto, as postagens também seguiram esse padrão. No início da pandemia, as recomendações preventivas estavam relacionadas ao isolamento social e ao fechamento do comércio, que foram incrementadas com regras enrijecendo a higiene pessoal e obrigando o uso de máscaras. Com a estabilização dos números de casos, os protocolos de prevenção impostos à população, que foram embasados na experiência dos países que já tinham enfrentado a primeira onda da Covid-19, deixaram de ser utilizados. A prefeitura passou a compartilhar mais informações baseadas nas decisões nacionais e estaduais, sejam essas do ministério da saúde ou do governo do estado.

Outro ponto a ser destacado sobre a codificação realizada na presente pesquisa, é em relação às ondulações dos volumes das postagens. Foi observado que, desde o primeiro caso confirmado na cidade, a página da prefeitura possui pelo menos uma publicação sobre a temática por dia. No entanto, pôde ser observado que existem picos mais expressivos a cada três dias, em média. Analisando os dias em que ocorreram esse aumento substancial das postagens sobre o novo coronavírus, observou-se que são nessas datas que ocorreram a maior sensibilização da população. Ou seja, são postagens referentes às campanhas educativas, para maior compreensão das medidas de prevenção.

A partir do exposto, e considerando os diversos desafios enfrentados pelos órgãos públicos, como a falta de investimentos e recursos humanos, a utilização das mídias sociais passa a ser uma estratégia econômica e eficiente de comunicação com os moradores das cidades (Santos, Harmata 2013). Elas são consideradas como ferramentas de baixo custo para a interação pública, já que podem ser utilizados programa gratuitos, além dos recursos já existentes, como computadores e internet (Santos 2016). Além disso, o uso de ferramentas digitais permite um serviço mais rápido e eficiente, sendo possível disponibilizar informações online que ajudem a população na solução de problemas. Situação essa que pode ser mais burocrática e demorada por outros canais de comunicação (Santos, Harmata 2013). Entende-se, portanto, que as vantagens são significativas quanto a utilização das mídias sociais para os órgãos públicos, principalmente ao avaliar os custos envolvidos no processo (Santos 2016).

As prefeituras também têm feito o uso das redes para monitorar as publicações, a fim de compreender as necessidades e reinvindicações da população (Santana, Souza 2017). Essas análises, que buscam compreender a percepção da população diante à um problema enfrentado, são significativamente importantes para o desenvolvimento das cidades. A utilização de instrumentos complementares à indicadores tradicionais se faz essencial em tempos de crise (Ferentz, Garcias, Setim 2020). Por meio das interações dos usuários, os gestores públicos podem traçar perfis com os interesses da população, além de identificar as regiões mais carentes, os serviços que necessitam de atenção e a distribuição de despesas prioritárias. Com esse mapeamento, é possível subsidiar novas políticas públicas que supram a necessidade local, com base na percepção das próprias comunidades (Santana, Souza 2017). 


\section{CONCLUSÃO}

A presente pesquisa buscou avaliar as publicações realizadas pela página da Prefeitura Municipal de Curitiba no Facebook, sobre a pandemia do novo coronavírus. As mídias sociais têm se apresentado como uma forma inovadora de interação entre os órgãos públicos e a sociedade, onde, ao mesmo tempo em que se realiza a divulgação de informações sobre as ações da administração pública, também pode-se acompanhar a percepção dos usuários sobre os seus serviços (Santana, Souza 2017).

Com a realização da pesquisa, observou-se que o compartilhamento de informações pela Prefeitura de Curitiba cresceu gradualmente conforme o aumento nos registros de casos e óbitos pelo novo coronavírus nos primeiros meses de quarentena. Com enfoque na saúde, as maiores publicações são sobre a comunicação do que está acontecendo em tempo real, a sensibilização e educação dos usuários quanto às medidas de proteção e prevenção à doença e os relatórios de atividades realizadas pela prefeitura.

As análises das mídias sociais de gestões municipais são essenciais para a proposição de melhorias contínuas de ações futuras (Santos, Harmata 2013). Por isso, como limitação da pesquisa, ressalta-se que a análise estatística do conteúdo curtido, comentado e compartilhado, não permite compreender o que o usuário faz com a informação recebida. Desse modo, para futuros trabalhos, além de poder aplicar a presente metodologia em outras cidades, utilizando-se de outras páginas oficiais do Facebook, seria interessante realizar uma análise aprofundada, de forma amostral, das interações dos usuários a partir das postagens realizadas pela prefeitura.

\section{FINANCIAMENTO}

O presente trabalho foi realizado com apoio da Coordenação de Aperfeiçoamento de Pessoal de Nível Superior - Brasil (CAPES) - Código de Financiamento 001.

\section{REFERÊNCIAS}

AVAAZ. O Brasil está sofrendo uma infodemia de Covid-19. 2020. Disponível em: https://secure.avaaz.org/campaign/po/brasil_infodemia_coronavirus. Acesso em: 26 maio 2020.

BARRIENTO, André Luiz; TAVARES, Débora Cristina; LEITE, José Carlos. Redes Sociais e a prefeitura de Curitiba: o caso da página do Executivo Municipal no Facebook. In: CONGRESSO INTERNACIONAL COMUNICAÇÃO E CONSUMO. COMUNICON, 2015, São Paulo. Anais eletrônicos ... Disponível em: http://anaiscomunicon2015.espm.br/GTs/GT4/27_GT4-BARRIENTO_LEITE_TAVARES.pdf. Acesso em: 26 maio 2020.

BONSÓN, Enrique, CARVAJAL-TRUJILLO, Elena; ESCOBAR-RODRÍGUEZ, Tomás, 2015. Corporate Facebook and stakeholder engagement. Kybernetes, v. 44, p. 771-787, 2015.

BONSÓN, Enrique, ROYO, Sonia e RATKAI, Melinda, 2015. Citizens' engagement on local governments' Facebook sites: an empirical analysis: the impact of different media and content types in Western Europe. Government Information Quarterly, v. 32, p. 52-62, 2015. 
BONSÓN, Enrique; ROYO, Sonia; RATKAI, Melinda. Facebook practices in Western European Municipalities. Administration \& Society, v. 49, p. 320-347, 2017.

BRASIL. Painel Coronavírus. 2020. Disponível em: https://covid.saude.gov.br/. Acesso em: 25 ago. 2020.

BROOKES, Erika. The anatomy of a facebook post: study on post performance by type, day of week, and time of day Vitrue-Oracle. New York, United States: Vitrue, 2010.

Disponível em: https://marketingavatar.files.wordpress.com/2010/11/the-anatomy-ofa-facebook-post.pdf. Acesso em: 25 ago. 2020.

CARVALHO, Gustavo Arthur Coelho Lobo de; KANFFER, Gustavo Guilherme Bezerra. O tratamento jurídico das notícias falsas (fake News). 2018. Disponível em: https://www.conjur.com.br/dl/tratamento-juridico-noticias-falsas.pdf. Acesso em: 25 ago. 2020.

CASTELLS, Manuel; CARDOSO, Gustavo (orgs). A sociedade em rede: do conhecimento à ação política. Imprensa Nacional: Brasília, 2006.

CURITIBA. Curitiba vence em duas categorias do maior prêmio brasileiro de mídias sociais. Curitiba, Paraná: Prefeitura Municipal de Curitiba, 2015. Disponível em: https://www.curitiba.pr.gov.br/noticias/curitiba-vence-em-duas-categorias-do-maiorpremio-brasileiro-de-midias-sociais/38234. Acesso em: 25 ago. 2020.

CURITIBA. Decreto municipal $n^{\circ} 450$. Estabelece medidas complementares para o enfrentamento da Emergência em Saúde Pública, decorrente do coronavírus (COVID19), no Município de Curitiba, $2020 a$.

CURITIBA. Decreto municipal $n^{\circ} 470$. Estabelece medidas complementares para o enfrentamento da Emergência em Saúde Pública, decorrente do novo Coronavírus (Covid-19) e define os serviços públicos e as atividades essenciais que devem ser resguardados pelo Poder Público e pela iniciativa privada. 2020b.

CURITIBA. Resolução n ${ }^{\circ}$. Estabelece medidas complementares e obrigatórias para o enfrentamento da Emergência em Saúde Pública, decorrente do novo Coronavírus e regulamenta o Decreto Municipal $n^{\circ} 470$, de 26 de março de 2020. 2020 c.

CURITIBA, 2020d. Portaria $n^{\circ} 6$. Dispõe sobre medidas para enfrentamento da emergência de saúde pública de importância internacional decorrente do coronavírus (COVID-19), no âmbito da Secretaria Municipal de Segurança Alimentar e Nutricional, de seus serviços e equipamentos. 2020d.

CURITIBA, 2020e. Plano de Contingência para reposta às emergências em saúde pública do município de Curitiba. 2020e.

CVIJIKJ, Irena Pletikosa; MICHAHELLES, Florian. A case study of the effects of moderator posts within a Facebook brand page. In: SOCIAL INFORMATICS INTERNATIONAL CONFERENCE, 3., 2011, Singapore. Proceedings... 2011. p. 161-170, 2011.

DE ROSARIO, Arturo Haro; MARTíN, Alejandro Saez; PÉREZ, Maria Del Carmen Caba. The use of Facebook to promote engagement with local governments in Spain. Social Media and Local Governments, v. 15, p. 219-241, 2016. 
DE VRIES, Lisette; GENSLER, Sonja; LEEFLANG, Peter. Popularity of brand posts on brand fan pages: an investigation of the effects of social media marketing. Journal of Interactive Marketing, v. 26, p. 83-91, 2012.

DESLANDES, Suely Ferreira; COUTINHO, Tiago. O uso intensivo da internet por crianças e adolescentes no contexto da Covid-19 e os riscos para violências autoinflingidas. Ciência e Saúde Coletiva, v. 25, p. 2479-2486, 2020.

DESVARS-Larrive, Amelie et al. A structured open dataset of government interventions in response to COVID-19. MedRxiv, 2020.

ELLISON, Nick; HARDEY, Michael. Developing political conversations?. Information, Communication \& Society, v. 16, p. 878-889, 2013.

FELDMAN, David et al. Communicating flood risk: looking back and forward at traditional and social media outlets. International Journal of Disaster Risk Reduction, v. 15, p. 1-24, 2016.

FERENTZ, Larissa Maria da Silva; GARCIAS, Carlos Mello; SETIM, Leana Carolina Ferreira. Proposta de um indicador de desenvolvimento sustentável com base na qualidade de vida, bem-estar e felicidade: estudo piloto na cidade de Curitiba, Brasil. Análise Social, v. 1, n. 234, p. 168-192, 2020.

HUANG, Chaoling et al. Clinical features of patients infected with 2019 novel coronavirus in Wuhan, China. Lancet, 2019.

JIN, Kang-Xing. Mantendo as pessoas seguras e informadas sobre o coronavírus. 2020. Disponível em: https://about.fb.com/br/news/2020/04/coronavirus/. Acesso em: 15 ago. 2020.

JOHANNESSEN, Marius Rohde; FLAK, Leif Skiftenes; SÆBØ, Øystein. Choosing the right medium for municipal eparticipation based on stakeholder expectations. electronic participation. 2012.

JÜNGER, Jakob e KEYLING, Till. Facepager: an application for generic data retrieval through APIs. 2020. Disponível em: https://github.com/strohne/Facepager/. Acesso em: 15 ago. 2020.

KANTAR. COVID-19 Barometer: consumer attitudes, media habits and expectations. 2020. Disponível em: https://www.kantar.com/Inspiration/Coronavirus/COVID-19Barometer-Consumer-attitudes-media-habits-and-expectations. Acesso em: 15 ago. 2020.

KEMP, Simon. Digital 2020: Brazil. 2020. Disponível em: https://bit.ly/2U0IXAO Acesso em: 15 ago. 2020.

KULSHRESTHA, Juhi; ESLAMI, Motahhare; MESSIAS Johnnatan; ZAFAR, Muhammad Bilal; GHOSH, Saptarshi; GUMMADI, Krishna; KARAHALIOS, K. Quantifying search bias: investigating sources of bias for political searches in social media. ArXiv Cornell University, v. 1, p. 417-432, 2017. 
LINDSAY, Bruce. Social media and disasters: current uses, future options, and policy considerations. CRS Report for Congress. Washington, DC: Congressional Research Service, 2011.

LUARN, Pin, LIN; Yu-Fan; CHIU, Yu-Ping. Influence of Facebook brand-page posts on online engagement. Online Information Review, v. 39, p. 505-519, 2015.

LUCAS, Benjamin; ELLIOT, Brendan; LANDMAN, Todd. Online information search during COVID-19. ArXiv Cornell University, v.1, p.1-13, 2020.

MAGRO, Michael. A review of social media use in e-government. Administrative Sciences, n. 2, 148-161, 2012.

MERGEL, Ines. The social media innovation challenge in the public sector. Information Policy, n. 17, p. 281-292, 2012.

MORENO, Ángeles; FUENTES-LARA, Cristina; NAVARRO, Cristina. Covid-19 communication management in Spain: exploring the effect of information-seeking behavior and message reception in public's evaluation. El profesional de la información, v. 29, n. 4, p. e290402, 2020.

MOURA, Rosa (coord.). A evolução tardia da COVID-19 na Região Metropolitana de Curitiba: Observatório das Metrópoles. 2020. Disponível em:

https://www.observatoriodasmetropoles.net.br/a-evolucao-tardia-da-covid-19-naregiao-metropolitana-de-curitiba/. Acesso em: 15 ago. 2020.

ORTIZ-OSPINA, Esteban; ROSER, Max. Loneliness and social connections. Disponível em: https://ourworldindata.org/social-connections-and-loneliness. Acesso em: 15 ago. 2020.

SABATE, Ferran; BERBEGAL-MIRABENT, Jasmina; CAÑABATE, Antonio; LEBHERZ, Philip. Factors influencing popularity of branded content in Facebook fan pages. European Management Journal, v. 32, p.1001-1011, 2014.

SANTANA, Marília Barreto; SOUZA, Cristiane Gabriela Boesing de. Uso das redes sociais por órgãos públicos no Brasil e possibilidades de contribuição do monitoramento para gestão. Revista Eletrônica de Gestão Organizacional, v.15, p. 99$107,2017$.

SANTOS, Gustavo Henrique Campos dos. O uso das mídias sociais no poder público: análise do perfil "Senado Federal" no Facebook. 2016. 148 f. Dissertação (Mestrado em Administração Pública) - Fundação João Pinheiro, 2016.

SANTOS, Janaína; HARMATA, Felipe. Análise de caso da Prefeitura de Curitiba: a relação entre humor e serviço público na comunicação em redes sociais. In: CONGRESSO DE CIÊNCIAS DA COMUNICAÇÃO NA REGIÃO SUDESTE, 18., 2013, Bauru. Anais... Intercom: Bauru, SP, 2013.

SBARAI, Rafael; HONORATO, Renata. Fotografia, o motor das redes sociais: o vídeo é visto como grande atração da web, mas são as fotos que animam a participação de usuários em serviços como o Facebook e o Pinterest. 2012. Disponível em: https://veja.abril.com.br/tecnologia/fotografia-o-motor-das-redes-sociais/. Acesso em: 15 ago. 2020. 
SHAMAN, Jeffrey; KARSPECK, Alicia; YANG, Wan; TAMERIUS, James; LIPSITCH, Marc. Real-time influenza forecasts during the 2012-2013 season. Nature Communications, v. 4, n. 1, p.1-10, 2013.

SHARMA, Megha; YADAV, Kapil; YADAV, Nitika; FERDINAND, Keith. Zika virus pandemic-analysis of facebook as a social media health information platform. American Journal of Infection Control, v. 45, n. 3, p. 301-302, 2017.

SILVA, Camila Mariane Costa. Uso de mídia social governamental para promover engajamento entre cidadãos e o governo federal. 2015. 210 f. Dissertação (Mestrado em Ciências) - Universidade de São Paulo, São Paulo, 2015.

SOUTHWELL, Brian; NIEDERDEPPE, Jeff; CAPPELLA, Joseph; GAYSYNSKY, Anna; KELLEY, Dannielle; PETERSON, Emily; CHOU, Wen-Ying Sylvia. Misinformation as a misunderstood challenge to public health. American Journal of Preventive Medicine, $v$. 57, n. 2, p. 282-285, 2019.

TWIST. Assessoria de Comunicação. Conheça a demografia das mídias sociais de 2019. 2020. Disponível em: https://www.twist.systems/pt-br/blog/2020/01/29/demografiadas-midias-sociais-de-2019/. Acesso em: 05 ago. 2020.

VIBOUD, Cécile; VESPIGNANI, Alessandro. The future of influenza forecasts. Proceedings of the National Academy of Sciences, v. 116, n. 8, p. 2802-2804, 2019.

VOSOUGHI, Soroush;ROY, Deb; ARAL, Sinan. The spread of true and false news online. Science, v. 359, n. 6380, p.1146-1151, 2018.

ZHANG, Liwei; LI, Huijie; CHEN, Kelin. Effective risk communication for public health emergency: reflection on the COVID-19 (2019-nCoV) outbreak in Wuhan, China. Healthcare, v. 8, n. 1, p. 64, 2020.

ZHU, Na; ZHANG, Dingyu; WANG, Wenling, Li; XINGWANG, YANG, Bo; SONG, Jingdong; ZHAO, Xiang; HUANG, Baoying; SHI, Weifeng; LU, Roujian; NIU, Peihua; ZHAN, Faxian; MA, Xuejun; WANG, Dayan; XU, Wenbo; WU, Guizhen; GAO, George; TAN, Wenjie. A novel coronavirus from patients with pneumonia in China, 2019. New England Journal of Medicine, n. 382, p. 727-733, 2020. 